stated, "almost exclusively nonsulphated". This does not detract, however, from the important finding of intense focal sulphomucin positivity in our case. We also agree that increased sulphomucins may be found in other epithelial sites in non-cystic fibrosis inflammatory disorders. In our paper we made no attempt to attribute directly the increased viscosity and other properties of cystic fibrosis mucus to increased sulphate production, though this was obviously implied. None the less, if this is the case it seems likely that the amount of sulphomucin produced, and not merely its presence, would be a decisive factor. Furthermore, any such effect would tend to be heightened in the terminal ileum due to the consistency of the faecal stream and the reduced diameter of the gut at the ileocaecal valve.

In 1965 Dr Lev and Dr Spicer stated that "the histochemically observed increase in sulfomucin (in cystic fibrosis) may be related to the abnormality of the secretion." While it is difficult to draw general conclusions from a single case we are surely implying no more than that. It is interesting that, 19 years on, Dr Lev appears to be modifying his conclusions in a letter to this journal.

I JEFFREY* M WELLS H FOX*

\section{Departments of Pathology, \\ *University of Manchester and University of Leeds}

\section{References}

' Morrissey SM, Tymvios MC. Acid mucins in human intestinal goblet cells. J Pathol 1978; 126: 197-208.

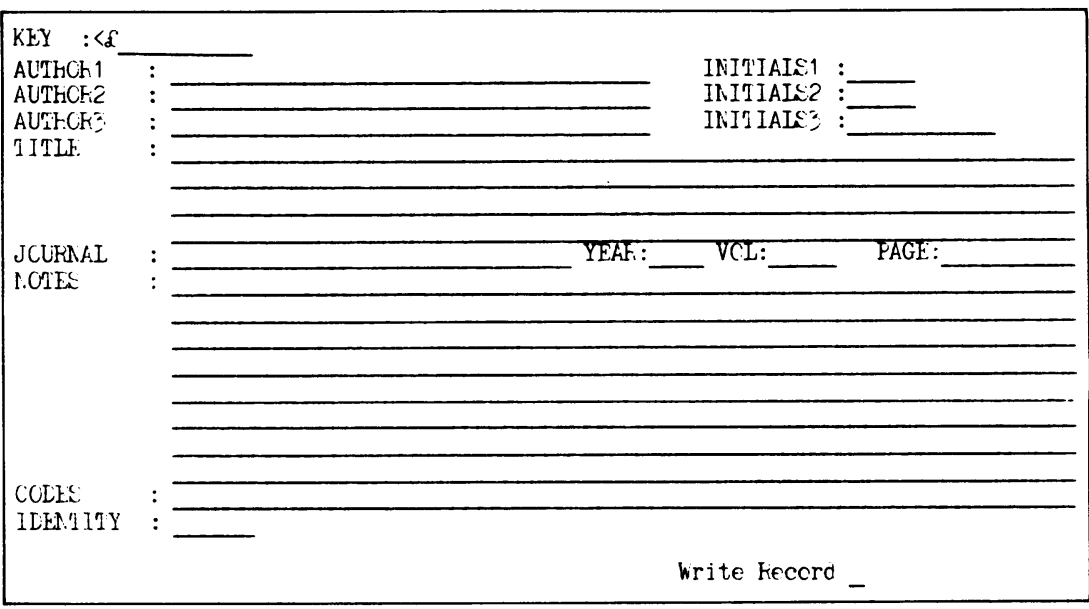

Fig. 1

numbers of cutaneous malignant melanoma, about 80-100 a year, and a special interest in this condition developed some years ago. With the advent of the histopathology computer (a DEC PDP 11/23) we took the chance to computerise the references gathered on this subjectcurrently about 300 . The computer was simply programmed to provide a format on to which details of each article can be entered (Fig. 1). This required about $1 \mathrm{~h}$ of work. The first three sections are for the author's details, and the choice of only the first three authors was quite deliberate; more could have been accommodated with ease. The next sections are for title, journal, year, volume, and page entries, followed by a section for an abstract or notes to be written. Finally, come the sections marked "codes" and "identity". We have categorised the melanoma published work into 29 subtypes according to a simple numerical system (Fig. 2). The relevant numbers are inserted into the "codes" section, depending on the nature of the article-for example, MM01 for an article $\vec{\varphi}$ concerning prognosis. Most articles cover more than one aspect of the 29 subsections and so several code entries for each article is common. The section "identity" allows individual consultants to identify those items which they have specifically inserted should this be so desired.

With all entries appropriately coded it is possible to identify with ease common groups of emphasis - for example, all papers concerned with melanoma thickness. The computer takes literally only a minute to identify these common groups and then offers the choice of a view or print option, either numerically or alphabetically. Similar selections, singly or in combination, can be made on other parameters - for example, author, journal, or year-thereby

\title{
Computers in histopathology
}

Details of our word and data processing system have already been published.'-4 The recent article by Dr Subbuswamy and others $^{5}$ prompts us to describe an unpublished aspect of our system: the reference storage and retrieval facility. This development has been made possible by the design of the histopathology system, which allows areas of new interest to be accommodated easily. Such flexibility is of major benefit and should be aimed for in all systems.

Our laboratory sees relatively large

\section{Formet of $\operatorname{cod} \epsilon=\mathbb{N} x \mathrm{x}$}

$1=$ Frognosis

$2=$ Tyre

$3=$ Imrunology

$4=\mathrm{histogenesis} \mathrm{\&} \mathrm{Lesional}$ evclution

$5=$ Eehavior (ciinical)

$6=$ largins

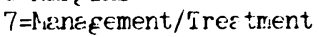

$\varepsilon=$ ihickness

$y=$ Levels

$10=$ Lpidemiology

$11=\mathrm{Histology}$
$12=$ Fe gression

$13=\mathrm{HN}$.

$14=$ Cther melanin tumours

$15=$ Lymphocytes

$16:=$ Il and other metastases

$17=$ f:etiol ogy

$1 \varepsilon=$ Staginf

$1 \mathrm{C}=$ Site

$2 \mathrm{C}=\mathrm{C}$ thers

$21=$ Chemistry

$2 z=$ Pethology

$23=$ Forcerline lesions
$24=$ Non-skin sites 25=Mixed lesions 26=Animels 27=Pregnarcy and Chilciren $28=$ Ircidence $2 \mathrm{C}=$ hecurrence

Fig. 2 
allowing detailed searches to be made; this is a useful feature for writing scientific papers.

The computer is also used to coordinate the National Melanoma Histology Club, which currently has 28 members. Automatic mailing through the "Mailshot" facility allows easy circulation of the club's slides with relevant clinical details. This circulation is accompanied by replies received with opinions about the last circulated slide, thereby allowing a rapid feedback of diagnoses. Each mailing also contains details of recent references, gathered from a variety of sources and supplied as a computer printout, as described above.

Although our emphasis to date has been on references relating to melanomas, this system is applicable for any form of specialised interest, and we are currently considering the possibility of inserting the published work which we have gathered over the years concerning pulmonary and oesophageal neoplasms.

\section{Book Reviews}

Ultrastructure of the Pulmonary Alveolar Lining Layer. JA Groniowski. (Pp 208; \$30.) National Technical Information Service, Springfield, VA. 1983.

This monograph provides a full account of the fine structure of pulmonary surfactant and the cells concerned in its production and development-ie, the alveolar epithelium and macrophages. It includes both transmission and scanning electron microscopy and deals with fixation methods essential to the proper preservation of the alveolar lining layer (which is generally disrupted by immersion fixation). The results of specialised techniques such as freeze fracture studies and fine structural cytochemistry are fully described and there is a brief section on the chemistry of surfactant. The author is mainly concerned with the normal lung but there is a final chapter considering the alveolar lining layer in the following disease states: hyaline membrane disease of the new born, respiratory distress syndrome of adults, pulmonary fibrosis, drug induced lung injury, and pulmonary alveolar lipoproteinosis. The book is well illustrated and very well referenced up to 1979. Items this reviewer noted with particular interest included early references in the French literature to the light microscopic recognition of type II pneumocytes and illustrations from the
A further major enhancement to the original histopathology system, using exactly the same approach as that described for references, is the melanoma database. The computer now contains details of more than 1200 cases of primary cutaneous malignant melanomas seen at the hospital since 1967. Each patient has up to 48 items of information recorded allowing, among other things, automatic mailing of the appropriate general practitioners for follow up purposes. Details of this aspect have been published elsewhere. ${ }^{\circ}$ We hope to apply this type of data bank to our cases of pulmonary and oesophageal tumours.

$$
\begin{array}{r}
\text { JAMES C BRIGGS } \\
\text { NASSIF BN IBRAHIM } \\
\text { IAN MACKINTOSH } \\
\text { DAVID NORRIS } \\
\text { Departments of Histopathology and } \\
\text { Medical Physics, } \\
\text { Frenchay Hospital, } \\
\text { Bristol BS16 1LE }
\end{array}
$$

author's own Polish language publications showing macrophages caught in transit between the alveolar interstitium and lumen. This book deals with a very specialised topic and can be recommended to those desirous of a good review of this area.

B CORRIN

Metabolic Disease. A Guide to Early Recognition. RM Cohn and KS Roth. (Pp 442; $£ 34 \cdot 75$.) WB Saunders Company. 1983.

This book is concerned mainly with inherited metabolic disorders. It is directed primarily to the general clinician but paediatricians are most likely to find it helpful. The authors have correlated clinical medicine with basic scientific knowledge. The first chapter is concerned with catastrophic metabolic diseases presenting in the newborn period and the second with biochemistry in metabolism. Thereafter follow 19 chapters concerned with pathophysiology and differential diagnosis of clinical derangements, 16 concerned with disorders of metabolism, and the final two cover laboratory evaluations. Many of the tables provide very useful check lists of disorders causing splenomegaly, mental retardation, or hypoglycaemia, or affecting the eyelids, for example. Lists of references are given after each chapter, and the dia-
References

' Briggs JC, Ibrahim NBN, Mackintosh I, Norris D. Computers in labpratories-The Frenchay system. Word and data processor in a Histopathology laboratory using a shared computer. Medical Technologist 1981; 11:22-3.

${ }^{2}$ Briggs JC, Ibrahim NBN, Mackintosh I, Norris D. The practical use of a word processor in a histology laboratory. J Clin Pathol 1982;35: 151-8.

${ }^{3}$ Briggs JC, Ibrahim NBN, Mackintosh I, Norris D. Word and data processing in histopathology laboratories. J Clin Pathol 1982;35: 1034-5.

${ }^{4}$ Briggs JC. Computers in histopathology. Bulletin of the Royal College of Pathologists 1983;42:7.

subbuswamy SG, McCormick A, Peters EE. Computerisation of histopathology/cytology records - use of a commercial data storage system. J Clin Pathol 1984:37:157-62.

- Briggs JC, Ibrahim NBN, Wickremaratchi T, Mackintosh I, Norris D, Griffiths RW. A Melanoma registry based on a computer run word and data processing system. Computers in Biology and Medicine 1984;14:245-52.

grams are very good. This volume is covering a specialised field; it will be a very useful addition to the medical library. BE CLAYTON

A Guide to Diagnostic Clinical Chemistry. RN Walmsley and GH White. (Pp 543; $£ 17 \cdot 50$.) Blackwells. 1983.

This is a new kind of Clinical Chemistry text book removed from mere repetition of patterns of chemical anomaly. The authors make extensive use of clinical case histories to illustrate and clarify the pathophysiology and practical use of relevant chemical pathology tests. I have no doubt that this approach is helpful to students for my review copy disappeared, and when I eventually rescued it from a member of the family busy with exams, I found it adulterated with green textline.

Water, electrolyte, and acid-base homeostasis are particularly well done in this book. There is an excellent chapter on the biochemical syndromes associated with tumours. Overall there is a good cover of chemical pathology applied to clinical medicine. There are, however, some deficiencies: vitamins, renal stones, inborn errors of metabolism, and other aspects of paediatric biochemistry are not covered and a small number of case histories, although true to real life, are confusing and 